\title{
REVISION AS PART OF THE WRITING PROCESS
}

\author{
ROSEMARY J. DE LUCA AND RICHARD S. WARD \\ Department of Arts and Language Education \\ University of Waikato
}

ABSTRACT This short report focusses upon revision and editing in children's writing. It describes how eight to twelve year old children perceived the role of revision and drafting and the relationship between drafting and publishing. Revision strategies for teachers are suggested.

\section{INTRODUCTION}

A glance at the achievement objectives for written language in the English in the New Zealand Curriculum (1994) document reveals an emphasis on genres, structures, and the mechanics and conventions of writing. There is also emphasis on the editing and reworking of texts. To develop an understanding about these things, young writers need to learn about texts and about how language works. In particular, they need to know how to revise their own writing. It is our belief that many young writers do not have the knowledge and skills to revise their own writing to a standard that many readers in the community expect.

We frequently hear criticisms in our communities and in our university staff rooms about the perceived low standard of writing among our young people. It was in response to such generalisations that we decided to look closely at one aspect of writing, that of revision. The new curriculum statement makes our investigation particularly timely.

We examined the perceptions about revision of writing of some of our students in their first year of study at university. We also looked at some of the writing practices in primary and intermediate schools. We found that writers at all three levels, somewhere in the process of writing, gave some attention to the importance of correct surface detail. However, they gave little attention to improving the communicative purpose of text by focusing on larger aspects such as purpose, audience, tone, genre, organisation, and clarity. And our impression is that even in attending to surface detail, students often lack the skills and knowledge to make the necessary changes for themselves.

\section{WRITERS AT THE PRIMARY AND INTERMEDIATE LEVELS}

We looked at the writings of a group of 20 eight, ten and twelve year old children. Their teachers had described these children as having average ability in writing. We asked them how they went about writing. Most described a process approach and many referred to what they did as "process writing"? In completing a writing task, they went through a series of stages that involved thinking of what to write about and the particular audience and form ( rehearsal ), making a draft copy ( first copy, rough copy), and publishing (final copy or neat copy). 
A comparison of draft copies with final copies indicated that errors in syntax and structure, and lack of clarity occurred in both copies, so that both copies were very similar. Therefore, we assumed that inaccuracies in drafts were frequently being transferred verbatim onto the final copies.

Discussion with each child focused on how each perceived the role of revision in drafting and also the relationship between drafting and publishing. These perceptions were noted.

1. Once written, a draft was rarely changed as a result of reading through the whole piece. Most revision occurred during drafting and usually entailed attention to small units of language: a change of word, a re-spelling of a word, or a small insertion.

2. The prime purpose for re-reading a draft was to check for spelling errors. At this stage of the process, there were quite clear strategies : re-read the piece for accuracy of conventions ( spelling, punctuation, and to a lesser extent, paragraphing ), show the piece to the teacher for editing, and rewrite a neat copy.

3. There was only a vague awareness of good models or demonstrations of revision. When asked to explain what was involved in the revision of a piece, most children explained revision in terms of attention to the surface features of writing. Questions about strategies such as restructuring the order in which events were introduced or the adequacy of information, were only vaguely understood. In addition, the children rarely recalled any recent demonstrations by the teacher of how to go about revision.

4. Conferencing rarely included any attention to improving the expression and style of the writing. Observations of conferences between teacher and pupil revealed that editing rarely included comment on the quality of expression. There was little discussion about what made the piece acceptable. Comments relating to the quality of a piece or a particular voice tended to be generalised and brief. One notable exception involved a teacher of the 12 year old group of writers who, during the daily readings to the class, frequently drew attention to the features of a particular style or the use of particular words. Some children tried to involve the examples in their writing, and the teacher commented on this when editing their work.

5. Teacher behaviour and pupil perception of what revision meant reinforced the notion of editor as corrector of "mistakes". In discussion about how they viewed revision, the four teachers involved in the study frequently mentioned their intention to attend to the surface features while not impairing the message of each script. Children saw their teacher's role as essentially that of corrector. They readily agreed that their teacher's editing taught them about the conventions of writing. For most pupils, their teacher's ideal of not changing the writer's "voice" or the message of the piece was seen as the teacher in the role of editor not responding to the whole intent and the need for clarity, but attending only to "mistakes". 


\section{UNIVERSITY STUDENTS REFLECT ON THEIR WRITING PRACTICES}

We surveyed 31 university students enrolled in a first year writing course. We asked them about the emphasis in their recent secondary school experience on revision as part of the writing process, and on technical (surface) correctness in writing. Many of the students surveyed claimed that neither revision of their writing nor technical correctness in writing received a lot of emphasis at secondary school. However, technical correctness was given more emphasis than revision of writing.

An assumption of this investigation was that the university students surveyed held a common understanding of the terms: revision of writing, the writing process, technical correctness. The survey was conducted part way through the writing course. In the early part of the course they had learned about the "stage approach" (process approach) to writing: invention, composition and revision, but also the recursive nature of writing in reality, that is, that these three activities frequently occur concurrently rather than in sequence. However, the course had made it clear that time must always be set aside, when the piece is more or less complete in its draft form, to read and revise it as a whole. Technical correctness was the term used in the course to denote traditional usage of the surface features of language, for example, correct spelling, complete sentences, formal grammar. Revision involved not only attention to surface features but also to larger elements of writing, such as the writer's purpose; clarity; meaning emphasised by means of structure; and language appropriate to the purpose and audience.

\section{RECOMMENDED REVISION STRATEGIES FOR TEACHERS IN THE CLASSROOM}

When teaching writing at the primary, intermediate and secondary school levels, there are a number of revision strategies to explain, use and model.

1. Using exemplary models of successful writing Pieces of writing judged by the teacher to be successful are distributed to the class. The emphasis in this exercise is on the larger or macro-aspects of writing. Answers are developed in smallgroup discussion to questions such as :

- Does the piece of writing work?

- What is the writer of this piece trying to achieve?

- Whom is the piece written for?

- Why has the writer chosen this genre?

- Why has the writer chosen this tone?

- Why has the writer chosen this level of vocabulary?

- Why are some sentences shorter or longer than others?

- What is happening in the first paragraph, the last paragraph, the intervening paragraphs?

- What would happen if we made paragraph 3 , for example, the last paragraph and put the last paragraph where paragraph 3 is? 
As well as analysing exemplary models, students are encouraged to apply these and similar analytical questions to their own writing and to that of their peers, and of their teachers.

2. Sharing writing to achieve clarity Shared writing involves two or more students jointly writing a piece. Questioning and discussion will often lead to close examination by the authors of what they are really trying to say, and then, as the piece nears the publication stage, whether the language suggested does actually say this. The piece may be tested for its clarity on readers who have not been involved in the writing of it.

3. Focusing on revision at the macro and micro-levels Here students re-work one of their paragraphs composed on an earlier occasion. They write the revised version onto an OHP transparency. The original, photocopied and distributed by the teacher, and the revised version are then discussed by the class. Questions are put to the revisers about why certain changes were made. The class may suggest further changes. The teacher will distinguish between macro and micro-level changes, and explain the effects of the changes.

4. Focusing on revision at the micro-level The students are encouraged as writers to proof-read their own writing for surface errors and check that appropriate conventions have been followed. The teacher's role in this exercise is to indicate, in advance, where changes need to be made, by circling each place with a pencil. Responsibility for the changes is clearly that of the writer not of the teacher. Students are thus encouraged to be independent writers.

\section{CONCLUSIONS}

We all want our students to be self-reliant, mature writers and communicators. Our investigations have led us to suggest some strategies for teaching writing in schools. These should help to redress what we see as a limitation in the way the process writing approach is sometimes followed. We recommend the use of good models of writing, clear explanation and application of revision strategies which involve close textual analysis with a specific focus and the acceptance by students themselves of the role of editor.

\section{REFERENCES}

English in the New Zealand Curriculum (1994). Wellington: Learning Media. Graves, D. (1982). Writing: Teachers and Children at Work. New York: Heinemann. Philips, D. (1983). Encouraging writing . Set, .2, Item 11.

Ward, R.S. (1992). Children's Conceptions of Writing in School and Out-of-School contexts. Unpublished M. Phil. Thesis. New Zealand: University of Waikato. 